\title{
Symptomatic Internal Carotid Artery Occlusion: \\ A long-term follow-up study
}

\author{
Suzanne Persoon, ${ }^{1}$ MD; Merel J.A. Luitse,${ }^{1}$ MD; Gert Jan de Borst,${ }^{2}$ MD, PhD; Albert \\ van der Zwan, ${ }^{3} \mathrm{MD}, \mathrm{PhD}$; Ale Algra, ${ }^{4} \mathrm{MD}, \mathrm{PhD} ; \mathrm{L}$. Jaap Kappelle, ${ }^{1} \mathrm{MD}, \mathrm{PhD}$; \\ Catharina J.M. Klijn, ${ }^{1} \mathrm{MD}, \mathrm{PhD}$
}

\footnotetext{
${ }^{1}$ Department of Neurology, Rudolf Magnus Institute of Neuroscience, University Medical Centre Utrecht, Utrecht, The Netherlands

${ }^{2}$ Department of Vascular Surgery, University Medical Centre Utrecht, Utrecht, The Netherlands

${ }^{3}$ Department of Neurosurgery, Rudolf Magnus Institute of Neuroscience, University Medical Centre Utrecht, Utrecht, The Netherlands

${ }^{4}$ Department of Epidemiology, Julius Centre for Health Sciences and Primary Care, University Medical Centre Utrecht, Utrecht, The Netherlands.
}

Correspondence to Suzanne Persoon, MD., Department of Neurology, University Medical Centre Utrecht, G03.228, Heidelberglaan 100, 3584 CX Utrecht, The Netherlands.

E-mail: s.persoon@umcutrecht.nl

Telephone number: +31 887557975

Fax number: +31302542100 
Word count: main text 3115 , abstract 250

Key words: Carotid Artery Diseases, Stroke, Follow-Up Studies 


\section{ABSTRACT}

Background: Information on outcome of patients with occlusion of the internal carotid artery (ICA) is limited by short duration of follow-up and lack of haemodynamic studies of the brain.

Methods: We prospectively investigated 117 consecutive patients with transient or moderately disabling cerebral or retinal ischaemia associated with ICA occlusion between September 1995 and July 1998 and followed them until June 2008. We determined the risk of recurrent ischaemic stroke and other vascular events and prognostic factors including collateral pathways and transcranial Doppler $\mathrm{CO}_{2}$-reactivity. Results: Patients (mean age $61 \pm 9$ years; $80 \%$ male) were followed for a median time of 10.2 years; 22 patients underwent endarterectomy for contralateral ICA stenosis and 16 extracranial/intracranial bypass surgery. Recurrent ischaemic stroke occurred in 23 patients, resulting in an annual rate of $2.4 \%$ (95\% confidence interval [CI], 1.5-3.6). Risk factors for recurrent ischaemic stroke were age (hazard ratio [HR] 1.07, 1.02-1.13), cerebral rather than retinal symptoms (HR 8.0, 1.1-60), recurrent symptoms after documented occlusion (HR 4.4, 1.6-12), limb-shaking TIAs at presentation (HR 7.5, 2.622), history of stroke (HR 2.8, 1.2-6.7) and leptomeningeal collaterals (HR 5.2, 1.5-17), but not $\mathrm{CO}_{2}$-reactivity (HR 1.01, 0.99-1.02). The composite event of any vascular event occurred in 57 patients, resulting in an annual rate of $6.4 \%$ (95\%CI, 4.9-8.2).

Conclusion: The prognosis of patients with TIA or minor stroke and ICA occlusion depends on age, several clinical factors and on the presence of leptomeningeal collaterals. 
The long-term risk of recurrent ischaemic stroke is much lower than that of other vascular events. 


\section{INTRODUCTION}

Patients with transient ischaemic attack (TIA) or ischaemic stroke associated with an occlusion of the internal carotid artery (ICA) have a risk of recurrent stroke of approximately 5-6\% per year.[1] In the subgroup of patients with symptomatic ICA occlusion in whom a compromised haemodynamic state of the brain has been demonstrated, this risk is around $12 \%$ per year.[2,3] The information on long-term outcome in patients with symptomatic ICA occlusion is limited by short duration of follow-up[2-4] or by lack of information about the flow state of the brain.[5-10] Since the large extracranial/intracranial (EC/IC) bypass trial did not show any benefit of bypass surgery in preventing recurrent stroke in patients with symptomatic ICA occlusion in general, $[10]$ the current standard treatment consists of antithrombotic medication and management of vascular risk factors. Whether an EC/IC bypass operation or carotid endarterectomy (CEA) of a contralateral ICA stenosis can prevent stroke in a subgroup of patients with symptomatic ICA occlusion is uncertain.[3,11-14] We previously reported the short-term outcome of a prospectively collected cohort of patients with symptomatic ICA occlusion.[15] The aim of the current follow-up study was to investigate the longterm outcome of this cohort and to study risk factors including haemodynamic characteristics for recurrent ischaemic stroke. 


\section{PATIENTS AND METHODS}

\section{Patients}

We prospectively included 117 consecutive patients with symptoms of transient or at most moderately disabling (modified Rankin scale, mRS $\leq 3$ )[16] cerebral or retinal ischaemia associated with an ipsilateral ICA occlusion, who were referred to the Department of Neurology at the University Medical Center Utrecht, The Netherlands between September 1995 and July 1998. All patients had had symptoms within 6 months prior to inclusion in the study. The presence of the ICA occlusion was confirmed by digital subtraction angiography showing absence of filling of the extracranial ICA or common carotid artery (CCA). Patients were excluded if the ICA occlusion was caused by dissection or radiation therapy. All patients were interviewed about clinical characteristics and risk factors as listed in Table 2, with special attention for clinical characteristics suggesting a haemodynamic cause of symptoms such as limb-shaking,[17] precipitation of symptoms by rising from a sitting or lying position, exercise, transfer from a cold to a warm environment, a decrease of blood pressure, or retinal claudication.[18] Furthermore, we documented whether patients had had ongoing symptoms after occlusion of the carotid artery had been demonstrated (but before inclusion in the study). All patients underwent magnetic resonance imaging (MRI) or computed tomography (CT) scan of the brain. Cerebral infarcts were considered symptomatic if their location corresponded with the patients' symptoms and were classified as territorial, watershed, lacunar (diameter $\leq 15 \mathrm{~mm}$ ) or large subcortical.[19] The degree of stenosis of the contralateral ICA was measured on the angiograms 
according to the NASCET criteria.[20] The presence of collateral pathways was assessed by the combined information from the angiogram and transcranial Doppler (TCD). Collateral pathways via either the anterior communicating artery $(\mathrm{ACoA})$ or the posterior communicating artery $(\mathrm{PCoA})$ were considered present if either of these showed at least filling of middle cerebral artery (MCA) branches on the angiogram or if TCD showed reverse flow in the first part of the anterior cerebral artery ipsilateral to the symptomatic ICA occlusion. Reversal of flow in the ipsilateral ophthalmic artery on TCD was considered a sign of collateral circulation via the external carotid artery. Leptomeningeal collaterals were considered present if pial branches from the posterior cerebral artery (PCA) extending as far as the vascular territory of the MCA or anterior cerebral artery (beyond the usual PCA territory) were visualised on the angiogram after selective catheterisation of one of the vertebral arteries beyond normal variability.[21] Patients underwent TCD with measurement of the $\mathrm{CO}_{2}$-reactivity to investigate cerebrovascular reserve capacity. The $\mathrm{CO}_{2}$-reactivity after carbogene inhalation was measured as the relative change in blood flow velocity in the MCA and expressed as a percentage as described previously.[15]

Treatment consisted of antithrombotic medication and management of vascular risk factors. Patients with a 70 to $99 \%$ stenosis of the contralateral ICA were offered CEA. Patients with symptoms of cerebral ischaemia that continued after documentation of the ICA occlusion and evidence of presumably haemodynamic origin (i.e. the presence of specific symptoms associated with a haemodynamic cause, a watershed infarct or low $\mathrm{CO}_{2}$-reactivity) were offered treatment with the high flow EC/IC bypass.[22] The study 
was approved by the institutional review board of the University Medical Center Utrecht and written informed consent was obtained from all patients.

\section{Follow-up and outcome}

Patients were followed at regular intervals in the outpatient clinic until November 1999. Final follow-up information was obtained by structured telephone interviews of the patients in June 2008. If the patient had died we obtained information of their relatives or their general practitioner. In case of a possible outcome event, we determined the mRS by a standardized questionnaire[23] and retrieved medical records and CT or MRI scans of the brain in case of recurrent stroke. The primary outcome was any first recurrent ischaemic stroke defined as the acute onset of new focal neurological deficit of cerebral origin persisting for more than 24 hours without hemorrhage on CT or MRI scan of the brain. The secondary outcome event was defined as the composite event of a non-fatal ischaemic or haemorrhagic stroke, non-fatal myocardial infarction (MI), or death due to vascular causes, whichever happened first.[15] Vascular death was defined as death from

fatal stroke, fatal MI, sudden death, terminal heart failure, systemic bleeding, pulmonary embolism or complications after vascular surgery. Fatal stroke was defined as death within 30 days after stroke or death after major stroke ( $m R S \geq 4$ ), in the absence of other clear causes.[24] Any death that was not clearly non-vascular, or if no information was available about the cause of death, was classified as 'other vascular.'[25] 


\section{Data analysis}

We determined annual rates of recurrent ischaemic stroke and of the combined outcome of vascular events with the Kaplan Meier method. The survival analysis started from the

time of inclusion in the study. We used a Cox proportional hazards model for univariable analysis of pre-defined risk factors for the primary and secondary outcome events, resulting in hazard ratios (HR) with $95 \%$ confidence intervals $(\mathrm{CI})$. The primary outcome recurrent ischaemic stroke was subdivided into any recurrent ischaemic stroke and only ipsilateral ischaemic stroke. Variables with a p-value $<0.15$ in the univariable analysis were included in a multivariable model. To exclude the influence of surgical treatment on the effect of pre-defined risk factors on the occurrence of the primary outcome event we also performed the Cox proportional hazards analysis with censoring of patients at the time of CEA of a contralateral ICA stenosis or at the time of an EC/IC bypass. 


\section{RESULTS}

In total we included 117 patients (mean age 61 years, range 35-79, 80\% male). Ninetythree $(80 \%)$ patients had presented with cerebral ischaemic symptoms, whereas $24(20 \%)$ patients had had only retinal ischaemic symptoms (retinal infarction in three, transient monocular blindness in 19 and chronic ocular ischaemic syndrome in five patients; three patients had two of these symptoms). Symptoms with haemodynamic characteristics were present in 16 patients; limb-shaking in nine, retinal claudication in three, symptoms after rising in five, after exercise in three and after low blood pressure in two patients. Seventy-eight (66\%) patients had a symptomatic infarct on their CT or MRI, that we classified as territorial in 31 patients, watershed in 32, lacunar in 11 and large subcortical in four patients. Of 117 patients, 40 (34\%) patients underwent a surgical revascularization procedure after a median of 46 days after inclusion (range 3-623 days). Twenty-two patients underwent CEA of a $70 \%$ to $99 \%$ contralateral ICA stenosis. One of them also had angioplasty for severe stenosis of the proximal part of the CCA on the side of the occlusion 14 days after the CEA because of recurrent TIAs. One patient underwent stenting of the contralateral ICA 20 months after inclusion in the study because of recurrent TIAs due to a contralateral ICA stenosis that had progressed from moderate to severe (>70\%). Another patient underwent endarterectomy of a $90 \%$ stenosis of the ECA. Sixteen patients underwent EC/IC bypass surgery. Six patients with a 70-99\% stenosis of the contralateral ICA chose not to be operated on and in another patient CEA was not possible because the stenosis extended to the carotid siphon. 


\section{Risk of recurrent ischaemic stroke}

The median follow-up time until recurrent ischaemic stroke or death was 10.2 years (range 7 days-12.8 years). None of the patients was lost to follow-up. Of the 117 patients, 52 (44\%) died during follow-up. Any recurrent ischaemic stroke occurred in $23(20 \%)$ patients, resulting in an annual rate of $2.4 \%$ (95\% CI, 1.5-3.6). The risk of any recurrent ischaemic stroke was highest in the first 1.5 years after presentation (Figure 1) (annual rate $8.0 \%, 95 \%$ CI 4.4-13.0). As shown in Table 1, 15 of the 23 patients had an ipsilateral ischaemic stroke, whereas eight ischaemic strokes occurred in another vascular territory. Nine of the 23 recurrent ischaemic strokes were major resulting in a $\mathrm{mRS} \geq 4$ (of which six were fatal) and 13 were at most moderately disabling strokes ( $\mathrm{mRS} \leq 3)$. In one patient we could not reliably determine the mRS because of co-morbidities. In three patients the (minor) ischaemic stroke occurred during the time they were waiting for the planned operation. Recurrent ischaemic stroke after the intervention occurred in six patients after an EC/IC bypass operation (four within 30 days, one after eight months and one almost 12 years after the operation), in two patients after CEA of the contralateral ICA (three and four years after surgery) and in one patient immediately after angioplasty of the CCA. Eleven of the $77(14 \%)$ patients who did not undergo a revascularization procedure had a recurrent ischaemic stroke. Two of them were known to have a contralateral ICA stenosis. The annual rate of recurrent ischaemic stroke in patients who did not undergo a revascularization operation was $2.1 \%$ (95\% CI 1.2-3.6).

\section{Risk factors for recurrent ischaemic stroke}


Table 2 shows the relationship between baseline characteristics and the recurrence of ischaemic stroke. Patients with cerebral symptoms had an eight times (age and sex adjusted HR 8.0, 95\% CI 1.1-60) higher risk of recurrent ischaemic stroke than patients

with retinal symptoms only. Continuation of symptoms after documented occlusion was associated with a four times (HR 4.5, 95\% CI 1.6-12) higher risk of recurrent ischaemic stroke. Other risk factors were older age (HR 1.07, 95\% CI 1.02-1.13), the presence of limb-shaking (HR 7.7, 95\% CI 2.6-22), history of stroke (HR 2.9, 95\% CI 1.2-6.7) and the presence of leptomeningeal collaterals on angiography (HR 5.1, 95\% CI 1.5-17). TCD $\mathrm{CO}_{2}$-reactivity was not predictive for the risk of recurrent ischaemic stroke (HR 1.01, 95\% CI 0.99-1.02). Bilateral ICA occlusion tended to be associated with a lower risk of recurrent ischaemic stroke (HR 0.2, 95\% CI 0.02-1.3). Because of the relatively small number of recurrent ischaemic strokes we refrained from further multivariable analysis. When we restricted the analysis to ipsilateral recurrent ischaemic stroke, age and sex adjusted risk factors were continuation of symptoms after documented carotid occlusion (HR 7.3, 95\% CI 1.7-33), limb-shaking (HR 7.8, 95\% CI 2.4-26) and leptomeningeal collaterals (HR 5.3, 95\% CI 1.2-23). After censoring the patients at the time of intervention, the age and sex adjusted factors continuation of symptoms after documented carotid occlusion (HR 3.7, 95\% CI 1.2-11) and older age (HR 1.07, 95\% CI 1.00-1.13) remained significantly associated with recurrent ischaemic stroke.

\section{Risk of the composite outcome of any vascular event}

Vascular outcome events occurred in 57 (49\%) patients. This included 28 vascular deaths (including six fatal ischaemic strokes, one fatal intracerebral haemorrhage, one fatal MI, 
six terminal heart failures, 11 sudden deaths, three other vascular causes), 17 non-fatal ischaemic strokes, one non-fatal intracerebral haemorrhage in the basal ganglia and 11 non-fatal MIs. Overall, of the 52 patients who died during follow-up the causes of death were vascular in 40 patients (in 28 vascular death as first event, in 12 vascular death after non-fatal stroke or MI as first event), and non-vascular in 12 patients (malignant disease in seven, infectious disease in three, renal disease in one, and an undiagnosed gradually progressive disease in one patient). The annual rate of the composite vascular endpoint was $6.4 \%$ (95\% CI, 4.9-8.2; Figure 1). Multivariable analysis showed that age (HR 1.06, 95\% CI 1.02-1.09; Table 3), a history of stroke (HR 1.9, 95\% CI 1.1-3.5) and a history of ischaemic heart disease (HR 1.8, 95\% CI 1.1-3.2) were independent risk factors for the occurrence of any vascular event. 


\section{DISCUSSION}

This 10-years follow-up study shows that patients with TIA or minor ischaemic stroke and ICA occlusion, treated with EC/IC bypass in case of recurrent symptoms of presumably haemodynamic origin or treated with CEA in case of contralateral ICA stenosis, have an annual risk of recurrent ischaemic stroke of $2.4 \%$, with the highest risk in the first 1.5 years after presentation. Elderly patients, those who present with cerebral instead of retinal ischaemic symptoms, patients with limb-shaking, recurrent symptoms after documented occlusion, a history of stroke, and those who have leptomeningeal collaterals on their angiogram have an increased risk of recurrent ischaemic stroke. $\mathrm{CO}_{2-}$ reactivity as measured with TCD did not predict recurrence of ischaemic stroke.

We were able to obtain a complete and very long duration of follow-up of a large cohort of well-documented prospectively studied patients. The largest study on outcome in patients with symptomatic ICA occlusion to date is the EC/IC bypass trial,[10] in which 423 patients who received best medical treatment were followed for 4.5 years. This study reported an annual rate of ischaemic stroke of $6.3 \%$, but measurements of the haemodynamic state of the brain were not performed. Other prospective follow-up series of patients with symptomatic ICA occlusion had a mean duration of follow-up of at most 4 years and found annual rates of ischaemic stroke between 5 and $10 \%,[3,4,6,26,27]$ except for one study that found an annual rate of 2\%.[9] Some of these studies also included patients who presented with major stroke.[4,6] The comparatively low recurrent stroke rate that we found can be explained in three ways. First, we showed that patients who present with symptomatic ICA occlusion have the highest risk of recurrent 
ischaemic stroke in the first 1.5 years and the risk of stroke is relatively low thereafter. Second, a considerable proportion of the patients in our study had presented with retinal ischaemic symptoms only. Patients with retinal symptoms only have a lower risk of ischaemic stroke than patients who present with cerebral ischaemic symptoms.[3,28] Third, over the last decades medical secondary prevention has improved with the introduction of statins,[29] dipyridamole in combination with aspirin[30] and more rigorous control of blood pressure.[31]

In contrast to other studies,[26,32] $\mathrm{TCD} \mathrm{CO} \mathrm{CO}_{2}$-reactivity in this study was not predictive of recurrent ischaemic stroke. In the previous studies the results may have been confounded by including asymptomatic as well as symptomatic patients. Asymptomatic patients have a relatively low stroke risk[33] and a relatively high cerebrovascular reactivity.[26] Similar to what we found after 2 years follow-up,[15] we found that the presence of leptomeningeal collaterals on the angiogram was predictive of recurrent ischaemic stroke. Although the role of these collaterals in the flow state of the brain needs further investigation, $[34,35]$ it is suggested that the finding of leptomeningeal collaterals is indicative of haemodynamic compromise.[36-38] The risk of the composite endpoint of any vascular event of $6.4 \%$ per year is relatively high when compared to the risk of $4 \%$ per year in patients with TIA or minor stroke not selected because of carotid disease,[30] probably indicating that patients with a symptomatic ICA occlusion have relatively severe generalised vascular disease.

This study was a single-center study. Patients with a symptomatic ICA occlusion were referred from all over the Netherlands to a tertiary university hospital and referral bias may have played a role. However, patients with frequent and ongoing symptoms are 
probably more likely to be referred than those with only one event and no further symptoms. Therefore, the risk of recurrent ischaemic stroke that we report would rather be over- than underestimated.

Another limitation of our study is that it does not reflect true natural history as we advised CEA in patients with a $>70 \%$ stenosis of the contralateral ICA and EC/IC bypass operation in selected patients with recurrent symptoms of cerebral ischaemia of presumed haemodynamic origin. Recently, another observational study showed that CEA of the contralateral ICA in 39 patients with symptomatic or asymptomatic ICA occlusion resulted in improvement of the vasomotor reactivity compared with 32 control patients who did not undergo CEA. However, they did not find a beneficial effect of CEA on the rate of recurrent stroke or death on long-term.[14] Although there is no evidence from randomized controlled trials that CEA of a contralateral ICA stenosis or EC/IC bypass operation can prevent stroke, we advised these operations because we estimated the risk of recurrent stroke to be high if patients were treated with best medical treatment only. Whether this treatment strategy may have prevented ischaemic stroke in some patients remains unclear. In fact, 5 operated patients suffered a stroke within 30 days of the operation and 4 of the 35 patients who were operated on without any complications suffered a recurrent stroke after on average 5 years. Because of the selection bias with regard to treatment, we could not statistically compare outcome in medically and surgically treated patients.

A third limitation is that the follow-up of our patients did not include serial duplex scanning or CT-angiography to reconfirm the occlusion after several years. Although infrequently, it has been described that spontaneous recanalization of an occluded ICA 
can occur, and a remaining high-grade stenosis would expose a patient at increased risk of an embolic event.[39]

Despite complete occlusion of the ICA, patients who have not suffered a major stroke at the time of occlusion have a relatively low risk of recurrent stroke, in particular once no stroke has occurred in the first 18 months. While this information is reassuring to the patients, it should be noted that their risk of other vascular events is significant and meticulous control of vascular risk factors is of key importance. Patients who continue to have symptoms after documentation of the ICA occlusion have a relatively high risk of recurrent ischaemic stroke. Although our study was not designed to evaluate the effectiveness of several treatment strategies, we suggest that particularly in patients with ongoing symptoms after documented occlusion and a contralateral ICA stenosis a CEA may be considered. EC/IC bypass surgery is associated with a considerable risk of postoperative stroke, in particular in unstable patients with repeated TIAs.[22] Whether or not EC/IC bypass surgery can prevent stroke in patients with demonstrated haemodynamic compromise will be answered by the ongoing Carotid Occlusion Surgery Study.[40] 
Table 1. Overview of the primary and secondary outcome events

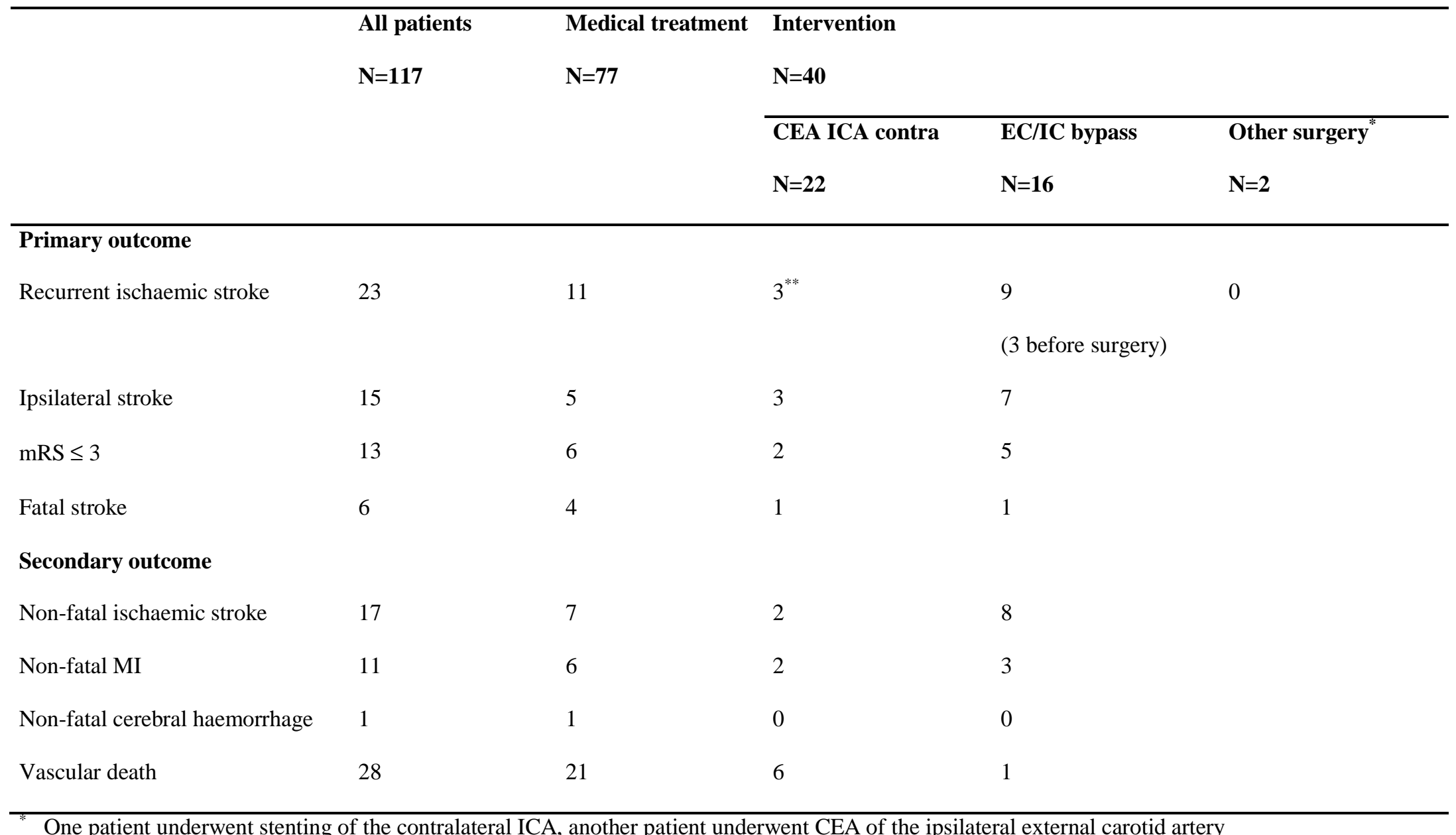

** One patient had the recurrent ischaemic stroke after angioplasty of the ipsilateral common carotid artery 14 days after CEA of the contralateral ICA 
Table 2. Analysis of risk factors for recurrent ischaemic stroke in patients with symptomatic ICA occlusion ( $\mathrm{n}=117)$

\begin{tabular}{|c|c|c|c|c|c|}
\hline & \multicolumn{2}{|c|}{ Ischaemic stroke } & \multirow[t]{2}{*}{ Univariable analysis } & \multirow{2}{*}{$\begin{array}{l}\text { Age and sex } \\
\text { adjusted analysis }\end{array}$} & \multirow{2}{*}{$\begin{array}{l}\text { Censored age and sex adjusted } \\
\text { analysis* }^{*}\end{array}$} \\
\hline & Yes & No & & & \\
\hline & $\mathbf{n}=\mathbf{2 3}$ & $\mathrm{n}=94$ & HR $(95 \% \mathrm{CI})$ & HR $(95 \% \mathrm{CI})$ & HR $(95 \% \mathrm{CI})$ \\
\hline $\mathrm{Age}^{* *}$ (years), mean $\pm \mathrm{SD}$ & $65 \pm 7$ & $60 \pm 9$ & $1.07(1.02-1.12)$ & $1.07(1.02-1.13)$ & $1.07(1.00-1.13)$ \\
\hline Cerebral symptoms at presentation & $22(96)$ & $71(76)$ & $6.0(0.8-45)$ & $8.0(1.1-60)$ & $4.3(0.6-34)$ \\
\hline - TIA & $7(30)$ & $16(17)$ & & & \\
\hline - Ischaemic stroke & $15(65)$ & $55(59)$ & & & \\
\hline Retinal symptoms only at presentation & $1(4)$ & $23(25)$ & & & \\
\hline Recurrent symptoms after documented & $18(78)$ & $38(40)$ & $4.7(1.7-13)$ & $4.5(1.6-12)$ & $3.7(1.2-11)$ \\
\hline \multicolumn{6}{|l|}{ occlusion } \\
\hline Current cigarette smoking & $16(70)$ & $70(75)$ & $0.8(0.3-2.0)$ & & $0.9(0.3-3.1)$ \\
\hline Hypertension & $11(48)$ & $51(54)$ & $0.8(0.3-1.7)$ & & $0.8(0.3-2.2)$ \\
\hline Diabetes Mellitus & $3(13)$ & $18(19)$ & $0.7(0.2-2.4)$ & & $1.1(0.2-5.1)$ \\
\hline
\end{tabular}




\begin{tabular}{|c|c|c|c|c|c|}
\hline Hyperlipidaemia $^{\dagger}$ & $19(83)$ & $80(85)$ & $0.9(0.3-2.5)$ & & $1.2(0.3-5.4)$ \\
\hline History of stroke & $9(39)$ & $18(19)$ & $2.6(1.1-6.1)$ & $2.9(1.2-6.7)$ & $3.0(0.96-9.3)$ \\
\hline History of ischaemic heart disease & $8(35)$ & $25(27)$ & $1.7(0.7-3.9)$ & & $0.5(0.1-2.3)$ \\
\hline History of peripheral vascular disease & $9(39)$ & $27(29)$ & $1.7(0.7-3.9)$ & & $1.4(0.4-4.4)$ \\
\hline History of vascular disease in first degree & $18(78)$ & $65(69)$ & $1.6(0.6-4.3)$ & & $2.0(0.6-7.4)$ \\
\hline \multicolumn{6}{|l|}{ relative } \\
\hline Contralateral carotid occlusion & $1(4)$ & $23(25)$ & $0.2(0.02-1.2)$ & $0.2(0.02-1.3)$ & $0.2(0.02-1.3)$ \\
\hline Contralateral carotid stenosis $\geq 70 \%$ & $5(22)$ & $24(26)$ & $0.8(0.3-2.1)$ & & $1.3(0.3-6.5)$ \\
\hline Collateral circulation via $\mathrm{ACoA}$ or $\mathrm{PCoA}^{\ddagger}$ & $20 / 20(100)$ & 70/73 (96) & $\mathrm{NE}$ & & $\mathrm{NE}$ \\
\hline Reverse flow in ophthalmic artery ${ }^{\S}$ & $15 / 18(83)$ & $67 / 75(89)$ & $0.5(0.1-1.7)$ & & $1.3(0.1-11)$ \\
\hline Leptomeningeal collaterals ${ }^{\mathbb{T}}$ & $7 / 15(47)$ & $14 / 61(23)$ & $2.5(0.9-6.9)$ & $5.1(1.5-17)$ & $2.0(0.3-11)$ \\
\hline $\mathrm{CO}_{2}$-reactivity ${ }^{\|}(\%)$, mean $\pm \mathrm{SD}$ & $21 \pm 33$ & $15 \pm 19$ & $1.01(0.99-1.02)$ & & $1.0(0.99-1.03)$ \\
\hline Watershed infarction ${ }^{\#}$ & 7/16 (44) & $25 / 62(40)$ & $1.1(0.4-2.9)$ & & $0.6(0.1-2.8)$ \\
\hline
\end{tabular}

*Analysis with censoring at the time of the first revascularization procedure

${ }^{* *}$ HR for age is expressed as the increase in hazard for every incremental year.

${ }^{\dagger}$ Defined as patients with either a history of hyperlipidaemia, patients on drugs because of hyperlipidaemia or patients with levels of cholesterol, triglycerides, or high density lipoprotein cholesterol beyond the normal ranges. 
${ }^{\ddagger}$ In 24 patients the presence of collateral circulation via either the ACoA or PCoA could not be determined.

$\S$ In 24 patients the flow direction in the ophthalmic artery could not be determined.

II In 41 patients the angiography was insufficient to define the presence of leptomeningeal collaterals.

${ } \mathrm{CO}_{2}$-reactivity ipsilateral to the symptomatic ICA occlusion could be measured in 21 of 23 patients and in 88 of 94 patients without a recurrent ischaemic stroke.

$\mathrm{HR}$ is expressed as the increase in hazard for every \% increase in $\mathrm{CO}_{2}$-reactivity.

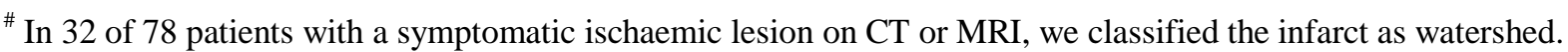

NE, not estimable. 
Table 3. Analysis of risk factors for any stroke, myocardial infarction or vascular death in patients with symptomatic ICA occlusion ( $\mathrm{n}=117)$

\begin{tabular}{|c|c|c|c|c|}
\hline & \multicolumn{2}{|c|}{$\begin{array}{l}\text { Any stroke, myocardial } \\
\text { infarction or vascular death }\end{array}$} & \multirow[t]{2}{*}{ Univariable analysis } & \multirow[t]{2}{*}{ Multivariable analysis } \\
\hline & Yes & No & & \\
\hline & $\mathbf{N}=57$ & $N=60$ & HR $(95 \%$ CI $)$ & HR $(95 \%$ CI $)$ \\
\hline Age (years), mean \pm SD & $64 \pm 9$ & $58 \pm 9$ & $1.06(1.03-1.09)$ & $1.06(1.02-1.1)$ \\
\hline Male & $47(83)$ & $47(78)$ & $1.1(0.6-2.2)$ & \\
\hline Current cigarette smoking & $42(74)$ & $44(73)$ & $1.1(0.6-1.9)$ & \\
\hline Hypertension & $32(56)$ & $30(50)$ & $1.2(0.7-1.9)$ & \\
\hline Diabetes Mellitus & $9(16)$ & $12(20)$ & $0.9(0.4-1.8)$ & \\
\hline Hyperlipidaemia & $48(84)$ & $51(85)$ & $1.0(0.5-2.0)$ & \\
\hline History of stroke & $17(30)$ & $10(17)$ & $1.9(1.1-3.3)$ & $2.0(1.1-3.5)$ \\
\hline History of ischaemic heart disease & $23(40)$ & $10(17)$ & $2.3(1.3-3.9)$ & $1.8(1.1-3.2)$ \\
\hline History of peripheral vascular disease & $19(33)$ & $17(28)$ & $1.4(0.8-2.4)$ & \\
\hline History of vascular disease in first degree relative & $43(75)$ & $40(67)$ & $1.3(0.7-2.4)$ & \\
\hline
\end{tabular}




\section{ACKNOWLEDGMENTS:}

S. Persoon is supported by a grant from the Netherlands Heart Association (grant number 2003B263) and the Foundation "De Drie Lichten" (grant number 41/09). C.J.M. Klijn was supported by a clinical fellowship from the Netherlands Organization for Health Research and Development (grant number 907-00-103).

\section{COMPETING INTERESTS:}

All authors declare that the answer to the questions on your competing interests form are all 'no' and therefore have nothing to declare.

\section{FUNDING:}

None

\section{COPYRIGHT:}

The corresponding author has the right to grant on behalf of all authors, an exclusive licence on a worldwide basis to the BMJ Publishing Group Ltd, and its Licensees to permit this article (if accepted) to be published in BMJ editions and any other BMJ PGL products and to exploit all subsidiary rights, as set out in our licence. 


\section{REFERENCES}

1 Klijn CJM, Kappelle LJ, Algra A, van Gijn J. Outcome in patients with symptomatic occlusion of the internal carotid artery or intracranial arterial lesions:

a meta-analysis of the role of baseline characteristics and type of antithrombotic treatment. Cerebrovasc Dis 2001;12:228-34.

2 Klijn CJM, Kappelle LJ, Tulleken CA, van Gijn J. Symptomatic carotid artery occlusion. A reappraisal of hemodynamic factors. Stroke 1997;28:2084-93.

3 Grubb RL, Jr., Derdeyn CP, Fritsch SM, Carpenter DA, Yundt KD, Videen TO, et al. Importance of hemodynamic factors in the prognosis of symptomatic carotid occlusion. JAMA 1998;280:1055-60.

4 Paciaroni M, Caso V, Venti M, Milia P, Kappelle LJ, Silvestrelli G, et al. Outcome in patients with stroke associated with internal carotid artery occlusion. Cerebrovasc Dis 2005;20:108-13.

5 Faught WE, van Bemmelen PS, Mattos MA, Hodgson KJ, Barkmeier LD, Ramsey DE, et al. Presentation and natural history of internal carotid artery occlusion. J Vasc Surg 1993;18:512-23.

6 Fields WS, Lemak NA. Joint study of extracranial arterial occlusion. X. Internal carotid artery occlusion. JAMA 1976;235:2734-8.

7 Furlan AJ, Whisnant JP, Baker HL, Jr. Long-term prognosis after carotid artery occlusion. Neurology 1980;30:986-8.

8 Flaherty ML, Flemming KD, McClelland R, Jorgensen NW, Brown RD, Jr. Population-based study of symptomatic internal carotid artery occlusion: incidence and long-term follow-up. Stroke 2004;35:e349-e352.

9 Persson AV, Griffey EE. The natural history of total occlusion of the internal carotid artery. Surg Clin North Am 1985;65:411-6. 
10 The EC/IC Bypass Study Group. Failure of extracranial-intracranial arterial bypass to reduce the risk of ischemic stroke. Results of an international randomized trial. N Engl J Med 1985;313:1191-200.

11 Markus HS, Harrison MJ, Adiseshiah M. Carotid endarterectomy improves haemodynamics on the contralateral side: implications for operating contralateral to an occluded carotid artery. Br J Surg 1993;80:170-2.

12 Rutgers DR, Klijn CJ, Kappelle LJ, Eikelboom BC, van Huffelen AC, van der Grond J. Sustained bilateral hemodynamic benefit of contralateral carotid endarterectomy in patients with symptomatic internal carotid artery occlusion. Stroke 2001;32:728-34.

13 Garrett MC, Komotar RJ, Starke RM, Merkow MB, Otten ML, Sciacca RR, et al. The efficacy of direct extracranial-intracranial bypass in the treatment of symptomatic hemodynamic failure secondary to athero-occlusive disease: a systematic review. Clin Neurol Neurosurg 2009;111:319-26.

14 Baracchini C, Meneghetti G, Manara R, Ermani M, Ballotta E. Cerebral hemodynamics after contralateral carotid endarterectomy in patients with symptomatic and asymptomatic carotid occlusion: a 10-year follow-up. J Cereb Blood Flow Metab 2006;26:899-905.

15 Klijn CJM, Kappelle LJ, van Huffelen AC, Visser GH, Algra A, Tulleken CA, et al. Recurrent ischemia in symptomatic carotid occlusion: prognostic value of hemodynamic factors. Neurology 2000;55:1806-12.

16 Banks JL, Marotta CA. Outcomes validity and reliability of the modified Rankin scale: implications for stroke clinical trials: a literature review and synthesis. Stroke 2007;38:1091-6.

17 Baquis GD, Pessin MS, Scott RM. Limb shaking--a carotid TIA. Stroke 1985;16:444-8. 
18 Furlan AJ, Whisnant JP, Kearns TP. Unilateral visual loss in bright light. An unusual symptom of carotid artery occlusive disease. Arch Neurol 1979;36:675-6.

19 Damasio H. A computed tomographic guide to the identification of cerebral vascular territories. Arch Neurol 1983;40:138-42.

20 Fox AJ. How to measure carotid stenosis. Radiology 1993;186:316-8.

21 van der Zwan A, Hillen B, Tulleken CA, Dujovny M. A quantitative investigation of the variability of the major cerebral arterial territories. Stroke 1993;24:1951-9.

22 Klijn CJM, Kappelle LJ, van der Zwan A, van Gijn J, Tulleken CA. Excimer laser-assisted high-flow extracranial/intracranial bypass in patients with symptomatic carotid artery occlusion at high risk of recurrent cerebral ischemia: safety and long-term outcome. Stroke 2002;33:2451-8.

23 Wilson JT, Hareendran A, Grant M, Baird T, Schulz UG, Muir KW, et al. Improving the assessment of outcomes in stroke: use of a structured interview to assign grades on the modified Rankin Scale. Stroke 2002;33:2243-6.

24 Halkes PH, van Gijn J, Kappelle LJ, Koudstaal PJ, Algra A. Classification of cause of death after stroke in clinical research. Stroke 2006;37:1521-4.

25 The CAPRIE Steering Committee. A randomised, blinded, trial of clopidogrel versus aspirin in patients at risk of ischaemic events (CAPRIE). Lancet 1996;348:1329-39.

26 Vernieri F, Pasqualetti P, Passarelli F, Rossini PM, Silvestrini M. Outcome of carotid artery occlusion is predicted by cerebrovascular reactivity. Stroke 1999;30:593-8.

27 Hankey GJ, Warlow CP. Prognosis of Symptomatic Carotid Artery Occlusion. Cerebrovasc Dis 1991;1:245-56. 
28 Streifler JY, Eliasziw M, Benavente OR, Harbison JW, Hachinski VC, Barnett $\mathrm{HJ}$, et al. The risk of stroke in patients with first-ever retinal vs hemispheric transient ischemic attacks and high-grade carotid stenosis. North American Symptomatic Carotid Endarterectomy Trial. Arch Neurol 1995;52:246-9.

29 Amarenco P, Labreuche J. Lipid management in the prevention of stroke: review and updated meta-analysis of statins for stroke prevention. Lancet Neurol 2009;8:453-63.

30 The Esprit study group. Aspirin plus dipyridamole versus aspirin alone after cerebral ischaemia of arterial origin (ESPRIT): randomised controlled trial. Lancet 2006;367:1665-73.

31 Zhang H, Thijs L, Staessen JA. Blood pressure lowering for primary and secondary prevention of stroke. Hypertension 2006;48:187-95.

32 Kleiser B, Widder B. Course of carotid artery occlusions with impaired cerebrovascular reactivity. Stroke 1992;23:171-4.

33 Powers WJ, Derdeyn CP, Fritsch SM, Carpenter DA, Yundt KD, Videen TO, et al. Benign prognosis of never-symptomatic carotid occlusion. Neurology 2000;54:878-82.

34 Brozici M, van der Zwan, Hillen B. Anatomy and functionality of leptomeningeal anastomoses: a review. Stroke 2003;34:2750-62.

35 Liebeskind DS. Collateral circulation. Stroke 2003;34:2279-84.

36 Hofmeijer J, Klijn CJ, Kappelle LJ, van Huffelen AC, van Gijn J. Collateral circulation via the ophthalmic artery or leptomeningeal vessels is associated with impaired cerebral vasoreactivity in patients with symptomatic carotid artery occlusion. Cerebrovasc Dis 2002;14:22-6.

37 Muller M, Schimrigk K. Vasomotor reactivity and pattern of collateral blood flow in severe occlusive carotid artery disease. Stroke 1996;27:296-9. 
38 Smith HA, Thompson-Dobkin J, Yonas H, Flint E. Correlation of xenonenhanced computed tomography-defined cerebral blood flow reactivity and collateral flow patterns. Stroke 1994;25:1784-7.

39 Nguyen-Huynh MN, Lev MH, Rordorf G. Spontaneous recanalization of internal carotid artery occlusion. Stroke 2003;34:1032-4.

40 Grubb RL, Jr., Powers WJ, Derdeyn CP, Adams HP, Jr., Clarke WR. The Carotid Occlusion Surgery Study. Neurosurg Focus 2003;14:e9. 


\section{FIGURE LEGEND}

Figure 1. Time-to-event curves for recurrent ischaemic stroke (upper part) and for any stroke, myocardial infarction or vascular death (lower part) in patients with symptomatic ICA occlusion $(\mathrm{n}=117)$ 


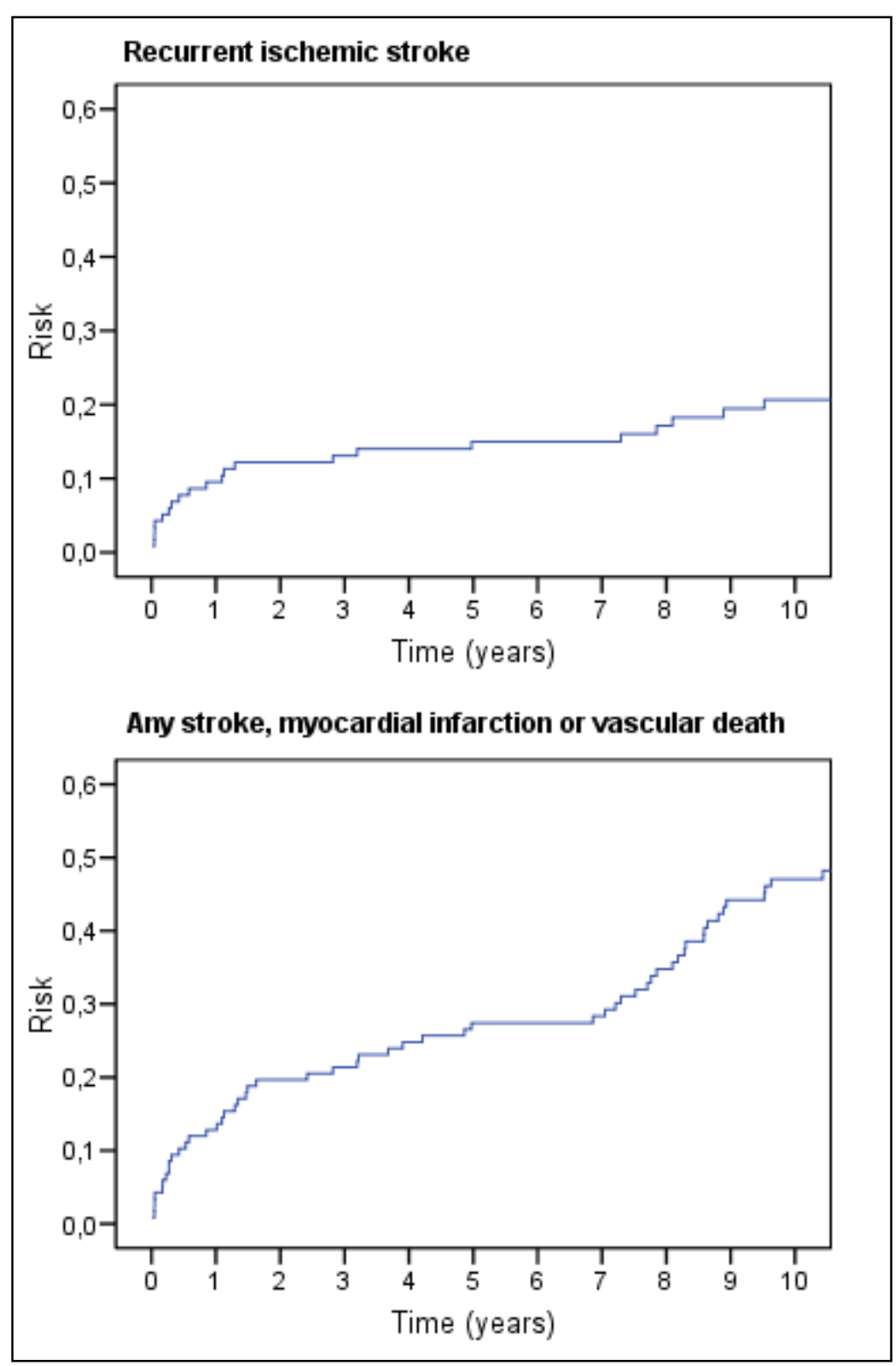

